\title{
Effect of Potassium Cyanide, Glucose and Anaerobiosis on Morphogenesis of Mucor rouxii
}

\author{
By MYRIAM FRIEDENTHAL, A. EPSTEIN AND \\ SUSANA PASSERON \\ Instituto de Investigaciones Bioquimicas 'Fundación Campomar' and \\ Facultad de Ciencias Exactas y Naturales, Obligado 2490, Buenos Aires 28, Argentina
}

(Received I8 June 1973; revised 5 December 1973)

\section{SUMMARY}

The morphological effect of potassium cyanide on the aerobic germination of spores of Mucor rouxii (NRRLI 894) in the presence of glucose was investigated. At concentrations of up to $2 \mathrm{mM}-\mathrm{KCN}$, normal filaments were formed; at concentrations of 3 to $6 \mathrm{~mm}$ intermediate forms were observed ranging from enlarged and septated hyphae to rounded multipolar cells; at $8 \mathrm{~mm}$ spores produced only budding spherical cells. The effect of glucose on the anaerobic germination of spores was also studied. At 0.01 \% glucose hyphal development occurred, whereas at increasing concentrations dimorphic colonies were formed. At $2 \%$ glucose purely yeast colonies appeared of the type described by Bartnicki-García (I968) for Mucor rouxii YM80. In the absence of glucose, or when glucose was replaced by xylose, maltose or succinate, spores did not germinate.

Anaerobiosis did not prevent the elongation of preformed hyphae obtained under aerobic conditions, provided that the cellular integrity was maintained. The anaerobic mycelia had a fermentative metabolism, as indicated by the low level of cytochrome oxidase, the amount and the type of pyruvate kinase, and the production of ethyl alcohol. Conversion of hyphal to yeast-like morphology was observed when tips of young hyphae were cultured in conditions favouring fermentation. The budding cells obtained were indistinguishable from yeast-like cells generated by anaerobic germination of spores.

\section{INTRODUCTION}

Vegetative development of Mucor rouxii may follow one of two patterns of morphogenesis depending on the growth environment. Under anaerobiosis spores germinate producing yeast-like cells (Y cells) which reproduce by budding, whereas aerobic development leads to the formation of a typical mycelium (M) (Bartnicki-García \& Nickerson, 1962 b). However, Terenzi \& Storck (1969) produced Y cells of $M$. rouxii (NRRLI894) under aerobic conditions, but only in the presence of phenethyl alcohol and provided that a hexose was present in the culture medium at a concentration above $2 \%(w / v)$. These $Y$ cells were characterized by an active aerobic fermentation.

Conversely, mycelial forms were obtained by Bartnicki-García (1968) under anaerobic conditions at glucose concentrations below $0.01 \%$. Higher concentrations of sugar stimulated the development of $\mathrm{Y}$ cells from spores but did not prevent the elongation of preformed hyphae obtained at low glucose concentration.

The yeast to mycelium transformation is readily observable when a culture of yeast is exposed to air. This conversion is accompanied by the synthesis of cytochrome oxidase, indicating that respiratory adaptation accompanies the transformation (Haidle \& Storck, I966). 
The present study was an attempt to explain the biochemical mechanism of mould-yeast dimorphism. The effect of potassium cyanide, a well known inhibitor of respiratory activity in many systems (Wainio \& Cooperstein, 1956; Lynen, Hartmann, Netter \& Schuegraff, I959) was studied during aerobic germination of spores of $M$. rouxii NRRLI 894 in the presence of glucose. The effect of glucose under anaerobic conditions and the effect of anaerobiosis on preformed hyphae were also investigated.

\section{METHODS}

Organisms. Mucor rouxii (NRRLI 894) was obtained from Dr G. W. Hesseltine (Northern Utilization Research and Development Division, Peoria, Illinois, U.S.A.).

Cultures and media. Spores of Mucor rouxii were produced and stored as described by Haidle \& Storck (I966). Unless otherwise indicated, cultivations were made in media containing yeast extract, peptone and glucose (YPG) prepared as described by Bartnicki-García $\&$ Nickerson $(1962 b)$. For solid cultures, Petri dishes containing $7 \mathrm{ml}$ of medium solidified with $2.5 \%(\mathrm{w} / \mathrm{v})$ agar were used. Sugar and succinate solutions were autoclaved separately from the yeast extract-peptone-agar and aseptically combined before being poured into the Petri dishes.

Potassium cyanide was added as a solid before inoculation in the case of large volume cultures $(700 \mathrm{ml})$. For small liquid cultures and solid cultures a concentrated solution of $\mathrm{KCN}$ was sterilized by filtration through a Millipore filter and added to the complete medium.

Aerobic liquid cultures were made on a rotatory shaker in Erlenmeyer flasks containing one-third to one-fifth their volumes of media. For anaerobic liquid cultures the volumes of media were five-sixths to nine-tenths that of the Erlenmeyer flasks, and incubations were done under $\mathrm{CO}_{2}$ atmosphere with magnetic stirring or on a reciprocating shaker; the flasks were flushed continuously with $\mathrm{CO}_{2}$, previously bubbled through alkaline pyrogallol, starting $2 \mathrm{~h}$ before spore inoculation. Anaerobic incubations of cultures on solid media were made in a desiccator containing a solution of alkaline pyrogallol. Air was replaced by $\mathrm{CO}_{2}$ by repeated evacuation and filling ( 7 times); the desiccator was connected to the $\mathrm{CO}_{2}$ tube and vacuum pump by means of a three-way stopcock in order to avoid re-entrance of oxygen.

All incubations were done at $28^{\circ} \mathrm{C}$. At the end of the incubation period, liquid cultures were harvested by filtration and the cells were rinsed with distilled water and kept at $-70^{\circ} \mathrm{C}$.

Transference of hyphae from aerobic to anaerobic cultures. Three agar plates containing $2 \%(\mathrm{w} / \mathrm{v})$ glucose were prepared as described, a small disc of sterilized filter paper $(0.8 \mathrm{~cm}$ diam) was layered on to the middle of each of the plates; and a suspension (Io $\mu \mathrm{l}$ ) containing $10^{3}$ spores $/ \mathrm{ml}$ was pipetted on to the paper. After $\mathrm{I} 8$ to $20 \mathrm{~h}$ of growth the centre was aseptically separated from the tips leaving a peripheral zone of hyphae I-2 $\mathrm{mm}$ wide. The agar plates with the hyphal tips still attached to the agar were washed three times with sterile water to remove any spores. The external hyphal zone was cut into small pieces and placed in a $250 \mathrm{ml}$ Erlenmeyer flask containing $200 \mathrm{ml}$ YPG medium $(5 \%, \mathrm{w} / \mathrm{v}$, glucose) and incubated anaerobically for $48 \mathrm{~h}$.

Production of anaerobic mycelia. A suspension $(0.1 \mathrm{ml})$ of $10^{3}$ spores $/ \mathrm{ml}$ was evenly inoculated on to the surface of an agar plate containing $2 \%(\mathrm{w} / \mathrm{v})$ glucose. After I 2 to I $4 \mathrm{~h}$ of aerobic incubation, mycelia appeared as small stars on the surface of the plate, each arising from one spore. Fifty of these mycelia were aseptically removed, transferred to liquid YPG medium ( $2 \%, \mathrm{w} / \mathrm{v}$, glucose) and incubated anaerobically for $48 \mathrm{~h}$. The 


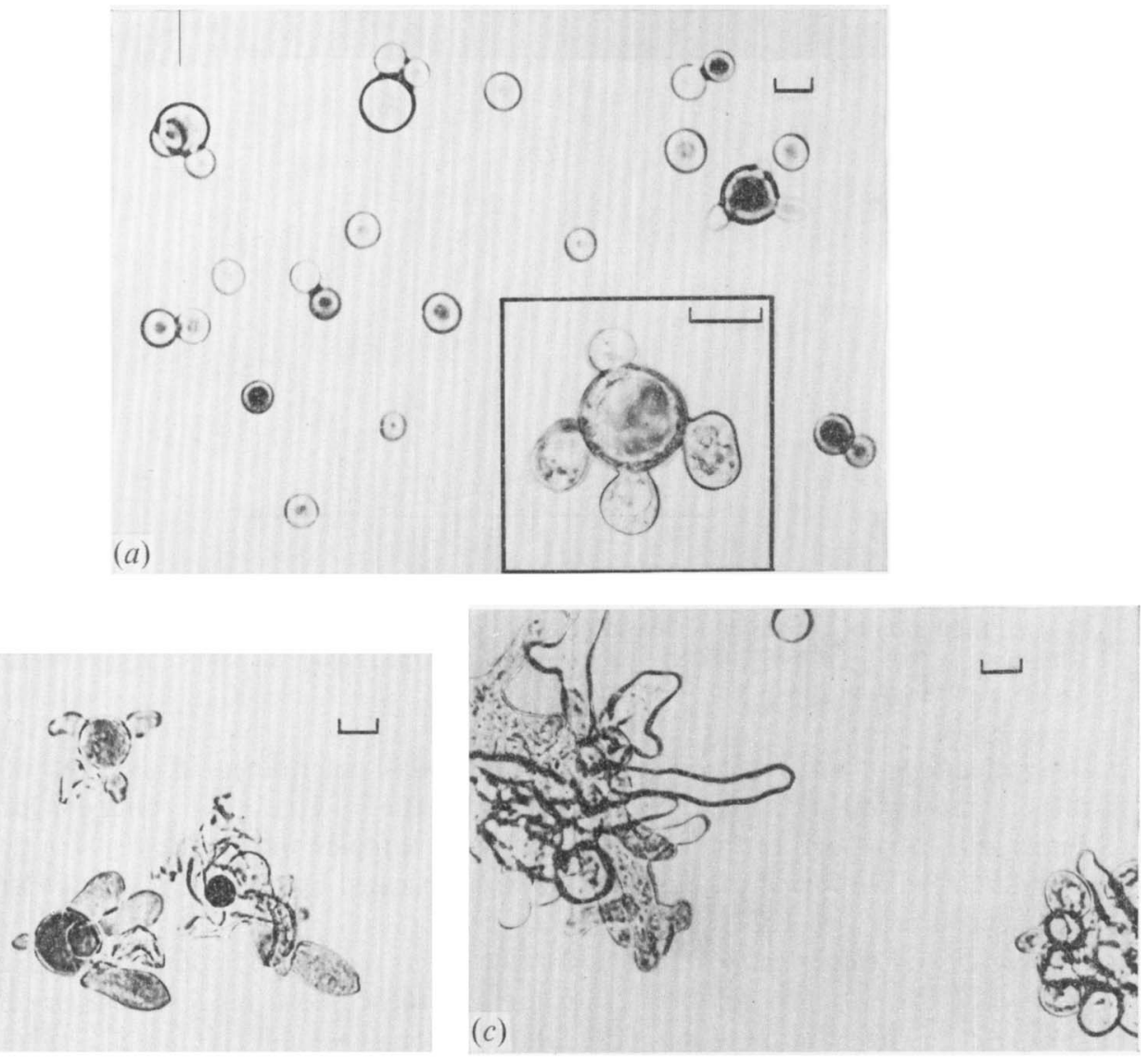

(b)

(c)
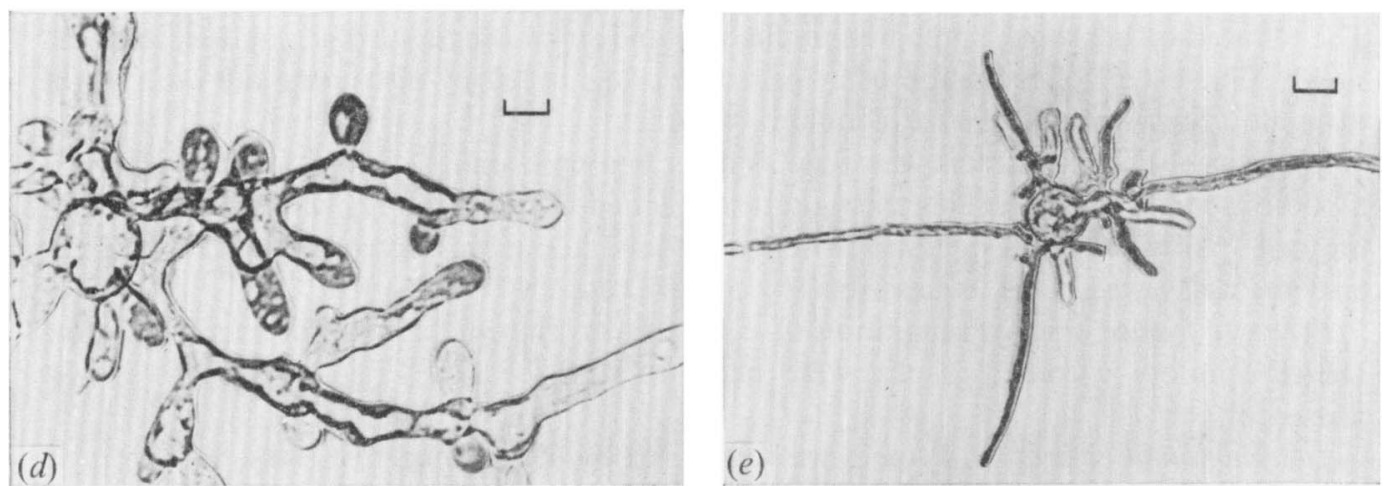

(e)

Fig. I. Effect of KCN concentration on dimorphism. Liquid cultures were incubated under air for $48 \mathrm{~h}$. The KCN concentrations were: (a) $8 \mathrm{mM}$; (b) $6 \mathrm{mM}$; (c) $5 \mathrm{mM}$; (d) $4 \mathrm{~mm}$; and (e) $3 \mathrm{~mm}$. Cultures $(a)$ and $(b)$ were stained with lactophenol-cotton blue. Bar marker $=10 \mathrm{~nm}$.

mycelia were filtered through Whatman No. I filter paper, resuspended in water, filtered again through two thicknesses of nylon mesh in order to eliminate the few spherical cells present among the filaments, rinsed with distilled water and kept at $-70^{\circ} \mathrm{C}$.

Measurement of growth. Cultures were filtered through tared filter paper discs, washed with distilled water, dried at $90{ }^{\circ} \mathrm{C}$ for $24 \mathrm{~h}$ and weighed. 


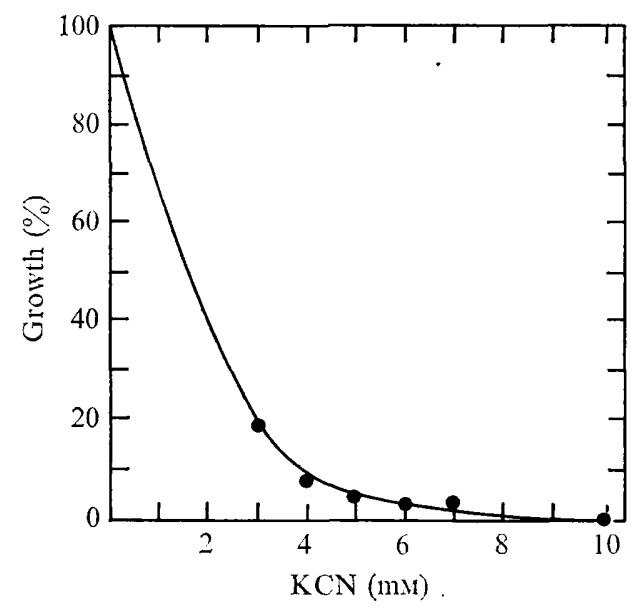

Fig. 2. Inhibition of growth by KCN. Liquid cultures were incubated aerobically in medium containing $5 \%(\mathrm{w} / \mathrm{v})$ glucose. Growth was expressed as a percentage of that of a control lacking $\mathrm{KCN}$. The spore inoculum was $10^{5}$ spores $/ \mathrm{ml}$.

Determination of ethyl alcohol. Ethyl alcohol was determined in samples of culture filtrates by measuring the NADH formed in the presence of excess of alcohol dehydrogenase (Bonnichsen, 1963). Before the enzymic assay, the samples were made $0.5 \mathrm{~N}$ in perchloric acid and kept on ice for $5 \mathrm{~h}$; the precipitate was separated by centrifugation and the supernatant neutralized with $\mathrm{KOH}$.

Cytochrome $c$ oxidase assay. The cytochrome $c$ was reduced by adding a slight excess of cysteine- $\mathrm{HCl}$ to a $100 \mu \mathrm{M}$ solution of oxidized cytochrome $c$ made in $0.01 \mathrm{M}$-phosphate buffer, $\mathrm{pH} 7 \cdot 0$. The solution was rapidly filtered through a small column of Sephadex G-25 extensively washed with de-aerated phosphate buffer immediately before the enzymic assay. The reduced cytochrome $c$ prepared in this way and stored under nitrogen autoxidized very slowly. The extent of reduction of cytochrome $c$ was tested by measuring the ratio of the extinction at $550 \mathrm{~nm}$ to the extinction at $565 \mathrm{~nm}$.

Preparation of cell extracts was done as described by Haidle \& Storck (1966) with slight modifications. Cycloheximide $(200 \mu \mathrm{g} / \mathrm{ml})$ was added to the cultures just before harvesting the cells. All subsequent operations were also done in the presence of cycloheximide. The enzymic assay was made as described by Smith (1955).

Pyruvate kinase assay. Preparation of cell extracts, enzymic activity determination and DEAE-cellulose chromatography were made as described by Friedenthal, Roselino \& Passeron (1973).

Determination of protein. Protein was measured by the method of Lowry, Rosebrough, Farr \& Randall (I95I), using bovine serum albumin as standard.

Chemicals. All chemicals were of analytical grade. Yeast alcohol dehydrogenase was purchased from Sigma.

\section{RESULTS AND DISCUSSION}

\section{Control of dimorphism by $K C N$}

Several examples in the literature demonstrate that inhibition of respiration and enhancement of fermentation always restrict morphological differentiation in filamentous fungi (Crocken \& Tatum, 1968; Terenzi \& Storck, 1969). 

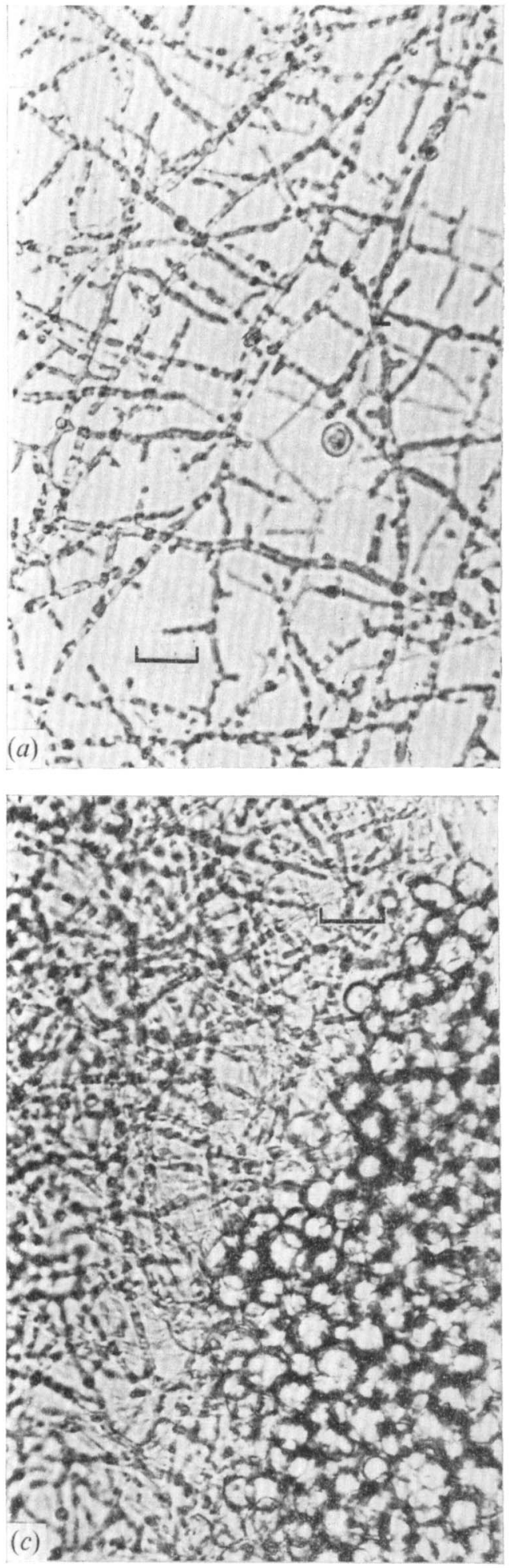
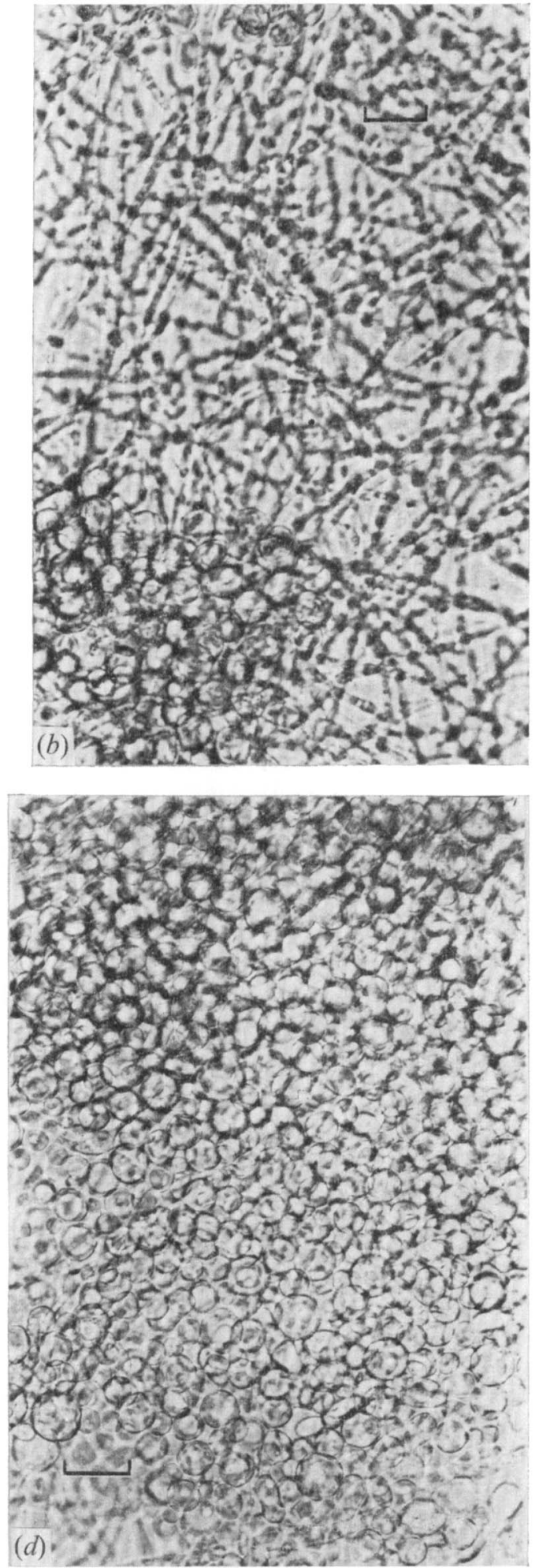

Fig. 3. Control of dimorphism by glucose concentration. Agar plates were incubated anaerobically as described in Methods. The glucose concentrations were (w/v): $(a) 0.01 \% ;(b) 0.025 \% ;(c) 0.05 \%$; and $(d) 2 \%$. Bar marker $=20 \mathrm{~nm}$. 


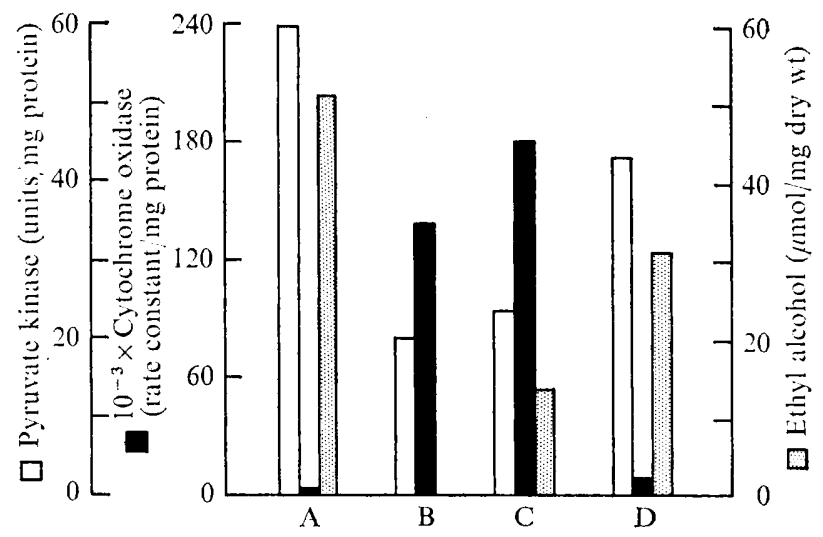

Fig. 4. Oxidative and fermentative capacity of the different forms of $M$. rouxii. A, yeast-like cells grown for $48 \mathrm{~h}$ in $2 \%(\mathrm{w} / \mathrm{v})$ glucose; B, ungerminated spores; C, aerobic mycelia grown for $\mathrm{I} 8 \mathrm{~h}$ in $2 \%(w / v)$ glucose; and D, mycelia grown anaerobically for $48 \mathrm{~h}$ in $2 \%(w / v)$ glucose.

Figure I shows the effect of potassium cyanide on the morphology of $M$. rouxii grown aerobically in the presence of $10 \%(\mathrm{w} / \mathrm{v})$ glucose. At the highest level of $\mathrm{KCN}(8 \mathrm{mM})$, the spores developed into spherical cells and buds can be observed which are typical of anaerobic yeast-like cells. At lower concentrations of $\mathrm{KCN}$ the fungus may develop into intermediate forms between mycelia and yeast cells. Cyanide seems to favour the broadening and shortening of hyphae to the point that at the highest concentration the unidirectional growth is replaced by a multipolar one and the cells and their progeny are nearly isodiametric. As can be seen in Fig. 2 these intermediate forms produced in the presence of $\mathrm{KCN}$ are obtained at the expense of severe growth inhibition.

Another effect of $\mathrm{KCN}$ is the remarkable delay in the germination of spores. After $24 \mathrm{~h}$ of incubation only swollen spores can be observed, whereas in cultures devoid of KCN germ tubes appear after 5 to $6 \mathrm{~h}$ of incubation.

\section{Control of dimorphism by glucose}

In anaerobic solid cultures at a glucose concentration of $0.01 \%$ the fungus developed exclusively as a thin mat of mycelia (Fig. 3). At $0.025 \%$ glucose small yeast colonies were formed surrounded by a halo of mycelia, at $0.05 \%$ glucose the yeast colonies were larger and the halo appeared later, whilst at $2 \%(\mathrm{w} / \mathrm{v})$ glucose, only yeast colonies were seen.

Spores inoculated in agar plates without glucose, or containing $5 \%(\mathrm{w} / \mathrm{v})$ of non-fermentable substrates such as xylose, maltose or succinate instead of glucose and incubated anaerobically, did not germinate. At $0.01 \%$ glucose, the inclusion of $\mathrm{KCN}$ in concentrations of up to $20 \mathrm{~mm}$ or chloramphenicol $(4 \mathrm{mg} / \mathrm{ml})$ did not change the morphology of the culture, that is, a thin mat of mycelia was obtained. These results seem to exclude the possibility that the dimorphic pattern observed was due to traces of oxygen in the atmosphere of incubation.

Our results are similar to those reported by Bartnicki-García (I968) for Mucor rouxii YM80. He also found that anaerobic liquid cultures responded to the glucose concentration in a similar way. However, when spores of Mucor rouxii NRRLI894 were incubated anaerobically in liquid medium at $0.0 \mathrm{I} \%$ glucose, germ tubes appeared after $48 \mathrm{~h}$ of incubation and did not elongate further; above that concentration the spores developed exclusively as Y cells; below $0.01 \%$ glucose spores did not germinate. 


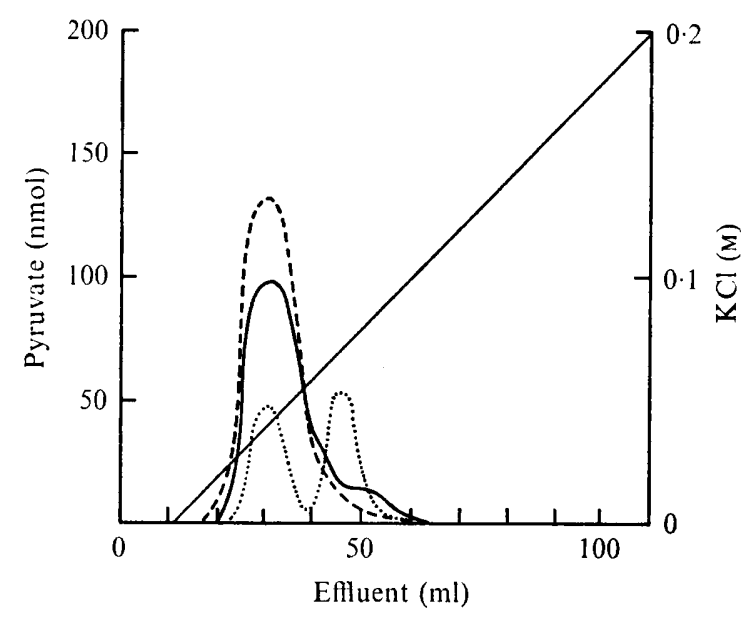

Fig. 5. Analytical DEAE-cellulose chromatography of extracts from $M$. rouxii : yeast-like cells (- -), aerobic mycelia (...), anaerobic mycelia (-). In each case $30000 \mathrm{~g}$ supernatant extracts containing 5 to Io $\mathrm{mg}$ protein were chromatographed. Portions of the fractions were tested for pyruvate kinase activity. Cultures were those described in"Fig. 4. Chromatographic details were as described by Friedenthal, Roselino \& Passeron (1973).

\section{Effect of anaerobiosis on aerobically grown mycelia}

Exposure of yeast-like cells to air induced their conversion to filaments. Haidle \& Storck (1966) reported that this transformation is accompanied by the synthesis of cytochrome oxidase. We found that at the moment of appearance of germ tubes this enzyme reached values 50 times that of $\mathrm{Y}$ cells. As shown in Fig. 4, aerobic mycelia grown in $2 \%(\mathrm{w} / \mathrm{v})$ glucose had a level of cytochrome oxidase 100 times that of $Y$ cells and similar to that found in sporangiospores.

Morphogenesis is accompanied by a change in the pattern of pyruvate kinase, a key glycolytic enzyme (Friedenthal, Roselino \& Passeron, 1973). Sporangiospores and Y cells possess only one form of the enzyme, type I; aerobic germination of spores or aeration of $\mathrm{Y}$ cells in a medium containing $2 \%(\mathrm{w} / \mathrm{v})$ glucose, is accompanied by the appearance of a new form of the enzyme, type II. After I 2 to $\mathrm{I} 4 \mathrm{~h}$ of aerobic incubation the activity of both isoenzymes is approximately equal, but the total activity is $30 \%$ that of the $\mathrm{Y}$ cells.

The transference of an aerobically grown mycelium to anaerobic conditions (see Methods) did not stop the apical growth and after $48 \mathrm{~h}$ of anaerobic incubation the biomass increased several hundred times. Although there was no change in morphology the metabolism corresponded to that of yeast cells. As can be seen in Fig. 4, the level of cytochrome oxidase decreased to near the trace values observed in yeasts. Figure 4 also shows that the yield of ethyl alcohol per mg dry weight was intermediate between aerobic mycelia and anaerobic yeast-like cells. At the same time pyruvate kinase activity approximated to the values observed in yeasts and, as can be seen in Fig. 5, the isoenzyme pattern was almost identical to that found in yeast cells. These results are compatible with the idea that a fermentative metabolism is not confined to the yeast morphology.

Bartnicki-García (1968) proposed a model in which a high level of fermentation promotes the accumulation of an unknown repressor of the apical growth. In conditions which impair fermentation, derepression or induction of hyphal morphogenesis takes place, and once the filamentous morphology is established it cannot revert to a yeast-like one. However, 

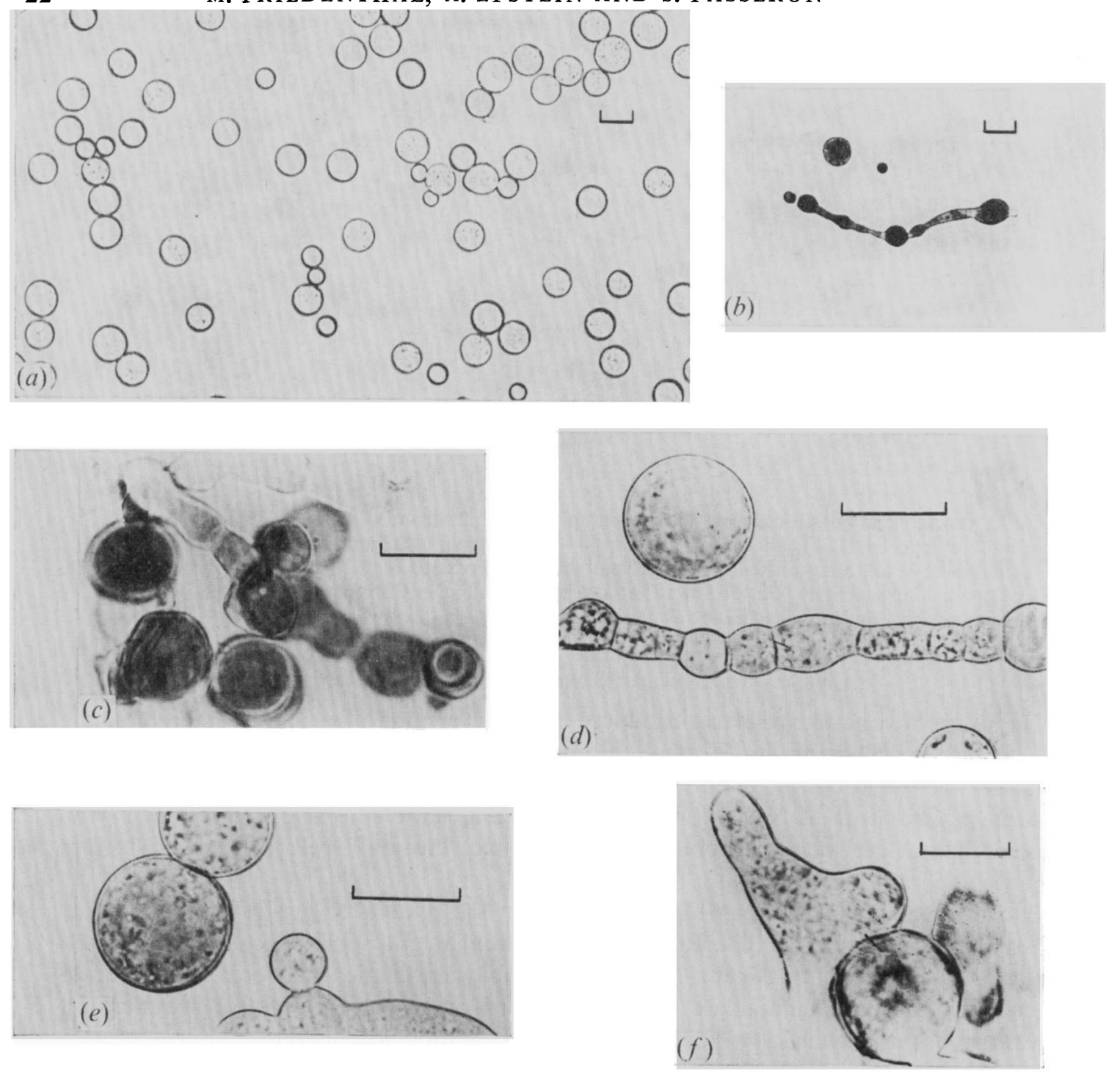

Fig. 6. (a) Yeast-like cells obtained from hyphal tips after $48 \mathrm{~h}$ of incubation under anaerobic conditions. Irregular swelling of the hyphal tips with the terminal and intercalary protuberances can be seen in $(b)$ to $(f)$. Cultures $(b)$ and $(c)$ were stained with lactophenol-cotton blue. Bar marker $=20 \mathrm{~nm}(a-e), 5 \mathrm{~nm}(f)$.

we found that in certain conditions the transformation of mycelium to yeast was possible. Budding yeast cells were obtained when the tips of young growing hyphae were excised, transferred to liquid media in the presence of a high level of glucose and incubated anaerobically (Fig. 6a). Tips coming from only 30 germinated spores produced as much as $240 \mathrm{mg}$ (wet weight) of budding yeast cells after $48 \mathrm{~h}$ of anaerobic incubation. The transitional structures shown in Fig. 6(b) to $(f)$ were always observed among the Y cells; the structures seem to be swollen hyphal fragments having the appearance of a string of beads. From the latter, spherical cells detach and multiply by budding, giving rise to typical yeast cells. 
Although Bartnicki-García \& Nickerson (1962a) reported the phenomenon of hyphal fragmentation which commences with the formation of septa at or near the tips of the filaments giving rise to spherical cells (arthrospores), they did not make a detailed study of the behaviour of these arthrospores under anaerobic conditions. The transformation that we describe is similar to the mycelium to yeast transformation reported for Paracoccidioides brasiliensis (Carbonell \& Rodríguez, 1965).

In view of the surprising amount of yeast cells obtained from I to $2 \mathrm{~mm}$ length tips derived from 30 spores, several controls were included to ensure that these yeast cells were not coming from ungerminated spores or from spherical cells present among the hyphal fragments at the time of transference to anaerobiosis. First, the spores were inoculated on a paper placed in the centre of the agar plate, as described in Methods. Second, the centre of the mycelial mat was cut off leaving the tips stuck to the agar, and the plate was then washed with distilled water. Third, the absence of spores, sporangia or spherical cells was routinely checked under the microscope in samples of the tips scraped from the agar.

Bartnicki-García considers the presence or absence of apical growth as the key factor determining whether Mucor develop into hyphae or Y cells respectively. Apical growth is regarded as the result of a derepression, when fermentation is impaired, of the enzymic complex responsible for localized cell wall synthesis. Though our results confirm that once the filamentous morphology is established, conditions favourable for yeast development do not stop the operation of apical growth, the capability to develop into yeast-like cells is not lost. In fact, as we describe, the transference of the youngest parts of aerobic hyphae to anaerobic conditions result in a shift from apical growth to multipolar growth, suggesting that the potentiality of hyphal tips to originate cells that reproduce by budding may represent a mechanism of survival in conditions in which normal hyphal development is impaired and sporulation cannot occur.

This investigation was supported in part by grants from the University of Buenos Aires and the Consejo Nacional de Investigaciones Científicas y Técnicas (Argentina). S.P. is a career investigator of the latter institution. We thank Dr J. E. Wright for his assistance with the light microscopy. We are also grateful to the members of the Instituto de Investigaciones Bioquímicas for their interest and helpful discussions, especially Dr M. Dankert and Dr I. D. Algranati.

\section{REFERENCES}

Bartnicki-García, S. (1968). Control of dimorphism in Mucor by hexoses: inhibition of hyphal morphogenesis. Journal of Bacteriology 96, 1586-1594.

BARTNICKI-GARCÍA, S. \& NICKERSON, W. J. (1962a). Induction of yeast-like development in Mucor by carbon dioxide. Journal of Bacteriology 84, 829-840.

BARTNICKI-GARCÍA, S. \& NiCKerson, W. J. (1962 b). Nutrition, growth and morphogenesis of Mucor rouxii. Journal of Bacteriology 84, 84I-858.

BonNICHSEN, R. (1963). Ethanol determination with alcohol dehydrogenase and DPN. In Methods of Enzymatic Analysis, pp. 285-287. Edited by H.-U. Bergmeyer. New York \& London: Academic Press.

Carbonell, L. M. \& Rodríguez, J. (1965). Transformation of mycelial and yeast forms of Paracoccidioides brasiliensis in cultures and in experimental inoculations. Journal of Bacteriology 90, 504-510.

Crocken, B. \& TATUM, E. L. (1968). The effect of sorbose on metabolism and morphology of Neurospora. Biochimica et biophysica acta 156, I-8.

Friedenthal, M., Roselino, E. \& Passeron, S. (1973). Multiple molecular forms of pyruvate kinase from Mucor rouxii. Immunological relationship among the three isoenzymes and nutritional factors affecting the enzymatic pattern. European Journal of Biochemistry 35, 148-1 58.

HAIDLE, C. W. \& STORCK, R. (1966). Control of dimorphism in Mucor rouxii. Journal of Bacteriology 92, I236-1244. 
Lowry, O. H., Rosebrough, A. L., FARr, A. L. \& RANDALl, R. J. (195I). Protein measurement with the Folin phenol reagent. Journal of Biological Chemistry 193, 265-275.

Lynen, F., Hartmann, G., Netrer, K. F. \& Schuegraff, A. (1959). Phosphate turnover and the Pasteur effect. In Ciba Foundation Symposium on the Regulation of Cell Metabolism, pp. 256-276. Edited by G. E. W. Wolstenholme \& C. M. O'Connor. London: Churchill.

SMITH, L. (1955). Spectrophotometric assay of cytochrome $c$ oxidase. In Methods of Biochemical Analysis, vol. 2, pp. 427-434. Edited by D. Glick. New York: Interscience Publishers.

TERENZI, H. F. \& StORCK, R. (I969). Stimulation of fermentation and yeast-like morphogenesis in Mucor rouxii by phenethyl alcohol. Journal of Bacteriology 97, I248-1261.

WaINIO, W. W. \& CoopersteIn, S. J. (1956). Some controversial aspects of the mammalian cytochromes. In Advances in Enzymology, vol. 17, pp. 329-392. Edited by F. F. Nord. New York: Interscience Publishers. 